\title{
Metaplastic Spindle Cell Breast Tumors Arising within Papillomas, Complex Sclerosing Lesions, and Nipple Adenomas
}

\author{
Helenice Gobbi, M.D., Ph.D., Jean F. Simpson, M.D., Roy A. Jensen, M.D., Sandra J. Olson, M.S., \\ David L. Page, M.D. \\ Department of Pathology, Division of Anatomic Pathology, Department of Preventive Medicine (HG, DLP, \\ JFS, SJO), and Departments of Cell and Cancer Biology (RAJ), Vanderbilt University Medical Center, \\ Nashville, Tennessee; and the Department of Anatomic Pathology, Federal University of Minas Gerais, \\ Belo Horizonte, Brazil (HG)
}

Micropapillomas/papillomas and complex sclerosing lesions of the breast have been associated with a slightly increased risk for subsequent carcinoma, although benign squamous metaplasia and reactive hypercellular stroma are seen within these lesions. There are few reports of these fibrosclerotic lesions associated with metaplastic tumors. Here we describe a series of metaplastic tumors arising within fibrosclerotic breast lesions. Thirty-three metaplastic tumors associated with fibrosclerotic lesions were selected from a breast pathology consultative practice. Relevant clinical and pathological features were reviewed. Representative sections were evaluated immunohistochemically for expression of cytokeratins, vimentin, and smooth muscle and muscle-specific actins. Both the metaplastic component (spindled and squamous cells) and the glandular elements were graded. The metaplastic tumors arose within papillomas ( 20 cases), complex sclerosing lesions (7 cases), both papilloma and complex sclerosing lesions ( 3 cases), and nipple adenoma ( 3 cases). A majority of the metaplastic tumors showed a dominant spindle cell component with various degrees of atypia, ranging from fibromatosis-like ( 16 cases) to low-grade ( 13 cases), intermediategrade ( 2 cases), and high-grade ( 2 cases) fibrosarcoma phenotype. Squamous metaplasia was present in 25 cases, and low-grade glandular

Copyright (C) 2003 by The United States and Canadian Academy of Pathology, Inc.

VOL. 16, NO. 9, P. 893, 2003 Printed in the U.S.A.

Date of acceptance: May 23, 2003.

Supported in part by the Division of Anatomic Pathology, Vanderbilt University Medical Center, Conselho Nacional de Desenvolvimento Científico e Tecnológico, and Fundação de Amparo a Pesquisa de Minas Gerais, Brazil.

Address reprint requests to: David L. Page, M.D., Vanderbilt University Medical Center, Department of Pathology C-3321 MCN, Nashville, TN 37232-2561; fax: 615-343-2317; e-mail: david.page@vanderbilt.edu.

DOI: 10.1097/01.MP.0000085027.75201.B5 elements, in 21 cases. Eleven tumors had a lowgrade adenosquamous growth pattern. Ductal carcinoma in situ was present in 7 cases, and invasive mammary carcinoma, in 5 cases. The very low-grade tumors were histologically similar to limited areas of stromal reaction and myofibroblastic proliferation, seen in partially sclerotic micropapillomas/papillomas and complex sclerosing lesions, but usually more cellular. Cytokeratin positivity $(13+/ 13$ tested) supports the metaplastic nature of the more plump spindled cells. The spindle cells were also positive for vimentin $(8+/ 8$ tested $)$ and smooth muscle $(2+/ 5$ tested) and muscle-specific actins $(6+/ 6$ tested). Spindle cell metaplastic tumors, from fibromatosis-like to fibrosarcoma, may arise within a variety of fibrosclerotic breast lesions.

KEY WORDS: Breast neoplasms, Complex sclerosing lesion, Metaplastic tumor, Papilloma, Spindle cell carcinoma.

Mod Pathol 2003;16(9):893-901

Micropapillomas and papillomas as well as complex sclerosing lesions of the breast have been associated with a slightly increased risk for subsequent development of carcinoma (1-3). Although benign squamous metaplasia and reactive hypercellular stroma are often seen within papillomas (4-7), there are few reports of such lesions associated with metaplastic tumors $(8,9)$. Recently, Denley et al. (10) described a series of metaplastic carcinomas of the breast arising within CSL. They postulate that there is a potential for sclerosing lesions of the breast to be associated with, and possibly give rise to, invasive carcinoma of different types.

Metaplastic tumors of the breast are a heterogeneous group of tumors, the majority of them with 
spindle cell differentiation that ranges from lowgrade fibromatosis-like lesions to high-grade fibrosarcomas (11-13). In this study, we describe a series of metaplastic breast tumors arising within complex fibrosclerotic breast lesions, including CSL/ radial scars, partially sclerotic and adenotic papillomas/MP, and nipple adenomas. We applied the term fibrosclerotic-epithelial lesion for such breast lesions showing mixed epithelial elements associated with complex, loose, and sclerotic tissue.

\section{MATERIALS AND METHODS}

Thirty-three cases of metaplastic tumors of the breast associated with fibrosclerotic lesions were selected from a series of 241 metaplastic tumors received as referral cases in the Breast Pathology Consultation Service at Vanderbilt University from 1985 to 2001. Relevant clinical and pathological features were reviewed. Histologic evaluation was performed using hematoxylin and eosin-stained sections, and the associated underlying breast lesions were noted using published diagnostic criteria (7, 14, 15). The metaplastic component was evaluated, considering the metaplastic tumor type and the spindle cell component grade (16). Presence and grade of glandular and squamous components were also noted.

Immunohistochemical stains were performed in 13 cases. A Ventana ES automated immunostainer was used (Ventana, Tucson, AZ), as well as the streptavidin-biotin-peroxidase methodology and antibodies against cytokeratins, vimentin, smooth muscle and muscle-specific actins, CD 31, Factor VIII, and desmin (Table 1) (12). Because of the limited availability of slides and blocks, not all antibodies were used in each case. When possible, a panel of anti-cytokeratin antibodies (Table 1) was used including AE1/AE3, CAM 5.2, cytokeratin 7

TABLE 1. Antibodies Used in This Study

\begin{tabular}{llll}
\hline \multicolumn{1}{c}{ Antibody } & \multicolumn{1}{c}{ Clone } & Dilution & \multicolumn{1}{c}{ Source } \\
\hline AE1/AE3 & AE1/AE3 & $1: 100$ & DAKO \\
HMW-K & Polyclonal, & Pre-dilute & SIGNET \\
& 40-60kD & & \\
CAM 5.2 & CAM 5.2 & $1: 20$ & Becton-Dickinson \\
Cytokeratin 7 & OV-TL 12/30 & $1: 100$ & DAKO \\
EMA & E29 & $1: 1000$ & DAKO \\
Vimentin & V9 & $1: 300$ & $\begin{array}{c}\text { Boehringer } \\
\text { Mannheim }\end{array}$ \\
Smooth muscle & CGA7 & Pre-dilute & ENZO \\
$\quad$ actin & & & \\
Muscle specific & HHF35 & Pre-dilute & ENZO \\
$\quad$ actin & & & \\
Factor VIII & F8/86 & $1: 40$ & DAKO \\
CD-31 & JC/70A & $1: 100$ & DAKO \\
\hline
\end{tabular}

HMW-K = high molecular weight keratin; EMA = epithelial membrane antigen.

* Thirteen out 13 cases tested were positive for epithelial markers.
(CK-7), and high molecular weight keratin (HMW$\mathrm{K})$. Positive and negative controls were run concurrently for all antibodies tested.

Clinical data and follow-up information including clinical presentation, age, sex, lymph node status, and site of involvement were obtained from medical records and referring physicians.

\section{RESULTS}

\section{Clinical Features}

The clinicopathologic features of all cases are summarized in Tables 2 to 5 . All patients were female, and the average age at initial diagnosis was 64.1 years (range, 24 to 84 y). Lesions involved the left breast in 20 cases and the right breast in 11; the side was not specified in 2 cases. One patient presented bilateral tumors. At the initial physical examination a single palpable breast mass was present in 27 patients, mass and nipple discharge in 2 patients, only nipple discharge in 1 patient, and abnormal mammogram in 3 patients.

\section{Pathology, Gross and Microscopic}

The tumor size, often including parts of the fibrosclerotic lesions, ranged from 0.9 to $6.0 \mathrm{~cm}$ in greatest dimension (average, $1.9 \mathrm{~cm}$ ). Twenty-four tumors were infiltrative and 9 were circumscribed; none was encapsulated. In 20/33 cases, the underlying lesions were papillary lesions including papilloma and/or multiple MP (Fig. 1). In 7 cases, the underlying lesions were CSL (Fig. 2), and 3 cases showed both complex sclerosing and papillary lesions. The other underlying diagnoses included 3 cases of nipple adenoma.

A majority of the metaplastic tumors showed a dominant spindle cell component with various degrees of atypia, ranging from fibromatosis-like (16 cases) to low-grade (13 cases), intermediate-grade ( 2 cases), and high-grade (2 cases) fibrosarcoma phenotype. Focally, plump fusiform and polygonal tumor cells, with more rounded nuclei, were arranged in "epithelioid" clumps (Fig. 1C). Foci of squamous metaplasia were present in 25 cases (Fig. $2, \mathrm{~B}-\mathrm{C}$ ), and low-grade glandular elements, in 21 cases. Eleven tumors had an adenosquamous growth pattern (Fig. 2C). Ductal carcinoma in situ was the epithelial component in 6 cases, and invasive mammary carcinoma, in 5 cases; 2 invasive carcinomas were of lobular variant. The very lowgrade tumors were difficult to differentiate from stromal reaction and myofibroblastic proliferation, which are very common in partially sclerotic MP/ papillomas and CSL. All cases showed features of both metaplastic tumor and fibrosclerotic breast lesion. Because CSL have pseudoinvasion of glands, 


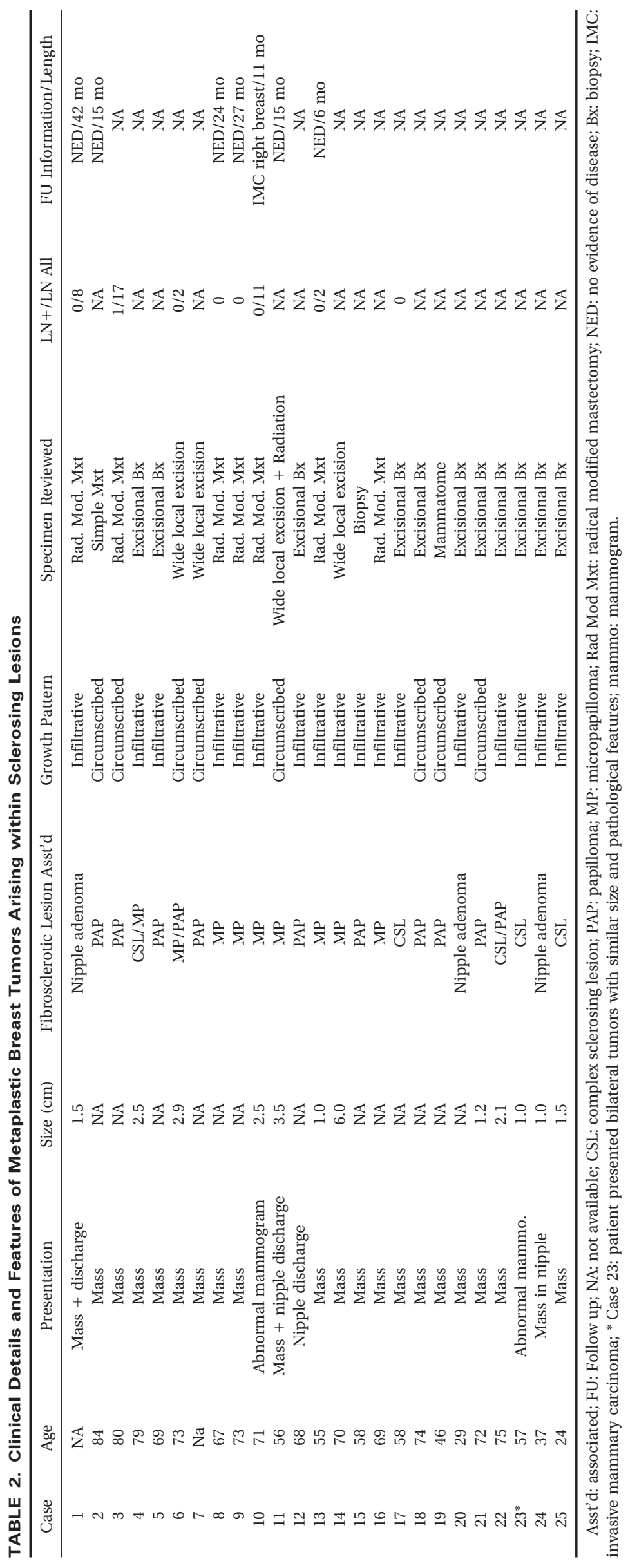




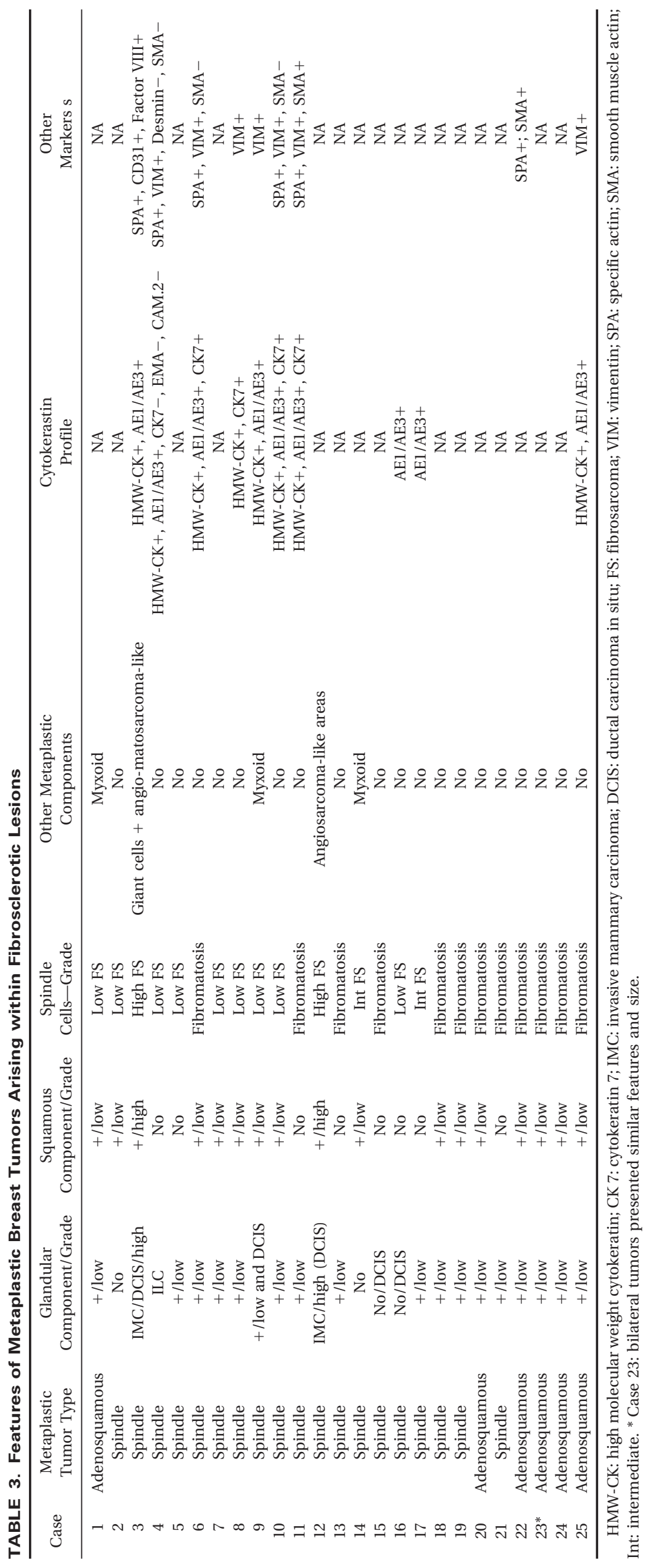


TABLE 4. Clinical Details and Features of the Recurrent Metaplastic Breast Tumors Arising within Fibrosclerostic Lesions

\begin{tabular}{cccccllll}
\hline Case & Age (yr) & Presentation & Size $(\mathrm{cm})$ & $\begin{array}{c}\text { Lesion } \\
\text { Asst'd }\end{array}$ & $\begin{array}{l}\text { Growth } \\
\text { Pattern }\end{array}$ & Specimen Reviewed & LN+/Total LN & FU Information/Length \\
\hline 1 & 62 & Mass & 1.5 & CSL & Infiltrative & Rad. Mod. Masect. & $0 / 10$ & Recurrence $2 \times / 72$ mo \\
2 & 70 & Mass & 1.2 & MP & Circumscribed & Rad. Mod. Mastect & $7 / 7$ & Recurrence $/ 29$ mo DOD \\
3 & 55 & Mass & 0.9 & PAP & Infiltrative & Wide local excision & $0 / 8$ & Recurrence $/ 96$ mo \\
4 & 77 & Mass & NA & CSL & Infiltrative & Rad. Mod. Mastect & $1 / 13$ & Recurrence $\times 2 ; 84$ mo \\
5 & 69 & Abnormal mammogram & NA & CSL & Infiltrative & Rad. Mod. Mastect & $0 / 8$ & Recurrence $/ 24$ mo \\
6 & 62 & Mass & 1.5 & CSL & Infiltrative & Rad Mod Mastect. & NA & Recurrence/84 mo \\
7 & 76 & Mass & 0.9 & CSL/MP & Infiltrative & Rad. Mod. Mastect & NA & Recurrence/36 mo \\
8 & 72 & Mass & NA & PAP & Infiltrative & Excisional biopsy & NA & Recurrence/24 mo \\
\hline
\end{tabular}

Asst'd: associated: FU: Follow up; NA: not available; CSL: complex sclerosing lesion; PAP: papilloma; MP: micropapilloma; Rad Mod Mxt: radical modified mastectomy; NED: no evidence of disease; Bx: biopsy; IMC: invasive mammary carcinoma. DOD: died of disease, with lung and brain metastasis.

TABLE 5. Features of the Recurrent Metaplastic Breast Tumors Arising within Fibrosclerotic Lesions

\begin{tabular}{|c|c|c|c|c|c|c|c|}
\hline Case & $\begin{array}{l}\text { Metaplastic } \\
\text { Tumor Type }\end{array}$ & $\begin{array}{c}\text { Glandular } \\
\text { Component/Grade }\end{array}$ & $\begin{array}{c}\text { Squamous } \\
\text { Component/Grade }\end{array}$ & $\begin{array}{l}\text { Spindle } \\
\text { Cells-Grade }\end{array}$ & $\begin{array}{l}\text { Other Metaplastic } \\
\text { Components }\end{array}$ & $\begin{array}{l}\text { Cytokeratin } \\
\text { Profile }\end{array}$ & $\begin{array}{l}\text { Other } \\
\text { Markers }\end{array}$ \\
\hline 1 & Adenosquamous & $+/$ low & $+/$ low & Low FS & Absent & NA & NA \\
\hline 2 & Spindle & ILC/DCIS & $+/$ low & Low FS/MFH & Osteoid & NA & NA \\
\hline 3 & Spindle & IMC & $+/$ low & Fibromatosis & No & NA & NA \\
\hline 4 & Adenosquamous & $+/$ low & $+/$ low & Fibromatosis & No & HMW-CK +, AE1/AE3+, CK7+ & NA \\
\hline 5 & Adenosquamous & $+/$ low & $+/$ low & Fibromatosis & No & HMW-CK +, AE1/AE3+, CK7+ & NA \\
\hline 6 & Adenosquamous & No & $+/$ low & Low FS & No & HMW-CK+, AE1/AE3+ & VIM+ \\
\hline 7 & Adenosquamous & $+/$ low & $+/$ low & Low FS & No & NA & NA \\
\hline 8 & Spindle & No (DCIS) & $+/$ low & Fibromatosis & No & NA & NA \\
\hline
\end{tabular}

+: present; HMW-CK: high molecular weight cytokeratin; CK 7: cytokeratin 7; IMC: invasive mammary carcinoma; DCIS: ductal carcinoma in situ; FS: fibrosarcoma; VIM: vimentin; SPA: specific actin; SMA: smooth muscle actin.

the borders or transitions to the neoplastic foci were often inapparent. Other findings were present focally in a few cases, such as storiform pattern resembling malignant fibrous histiocytoma (one case), fibromyxoid (three cases) and osteoid (one case) stroma, giant cells (one case), and low-grade angiosarcoma-like foci (two cases). Lymphoid reaction was present at the edges of the tumor or scattered in the lesion in 18/33 cases, with occasional lymphoid follicles, some with germinal centers.

\section{Immunohistochemical Studies}

Immunohistochemical analysis for epithelial markers was positive in 13/13 cases tested (Tables $3,5)$. The strongest marking was obtained with the antibodies against AE1/AE3 and HMW-K (Fig. 1, B-D). Normal ducts and lobules entrapped within the tumors were positive for all epithelial markers and were used as internal control. Weaker reactions were obtained for low molecular weight keratins (CAM 5.2 and CK-7). Both types of cells, epithelioid and spindled, expressed cytokeratins, but the epithelioid cells showed stronger cytoplasmic positivity (Fig. 1,B-D). Staining intensity gradually decreased in the transition to the spindle cell component. The squamous and glandular elements stained for all types of cytokeratins tested. The squamous component stained more strongly with HMW-K and AE1/AE3 than did glandular elements. Although not readily apparent in the hematoxylin and eosin-stained sections, the few glandular ele- ments present were very obvious in the sections stained for AE1/AE3 and CK-7 in the fibromatosislike tumors, and weak expression of HMW-K was observed. The spindle cells and some epithelioid cells expressed vimentin $(8+/ 8$ tested), but the intensity was stronger in the spindle cells. In six cases the spindle cells stained for muscle-specific actin, and in two cases they stained for smooth muscle actin.

\section{Treatment and Follow-Up}

Information about initial treatment was available for 18 of 33 patients (Tables 2, 4). Lymph node metastasis was present in 3/13 cases, and the primary tumors in those cases had a dominant carcinoma phenotype. In 1 case the primary tumor showed high-grade invasive carcinoma; another case presented invasive lobular variant component, and the third case had an adenosquamous pattern with a high proportion of the glandular elements. The metastasis in this case presented a solitary squamous cyst. In 20 cases, the lymph node status was not known. Follow-up information was available for 15 of the 33 patients (Table 2). The length of follow-up period ranged from 6 months to 96 months (average: $30.4 \mathrm{mo}$ ). Thirteen of those 33 women were treated with modified radical mastectomy, 1 with simple mastectomy, and 5 with wide local excision. In the other cases an excisional biopsy (11 cases) and a mammotome specimen (1 

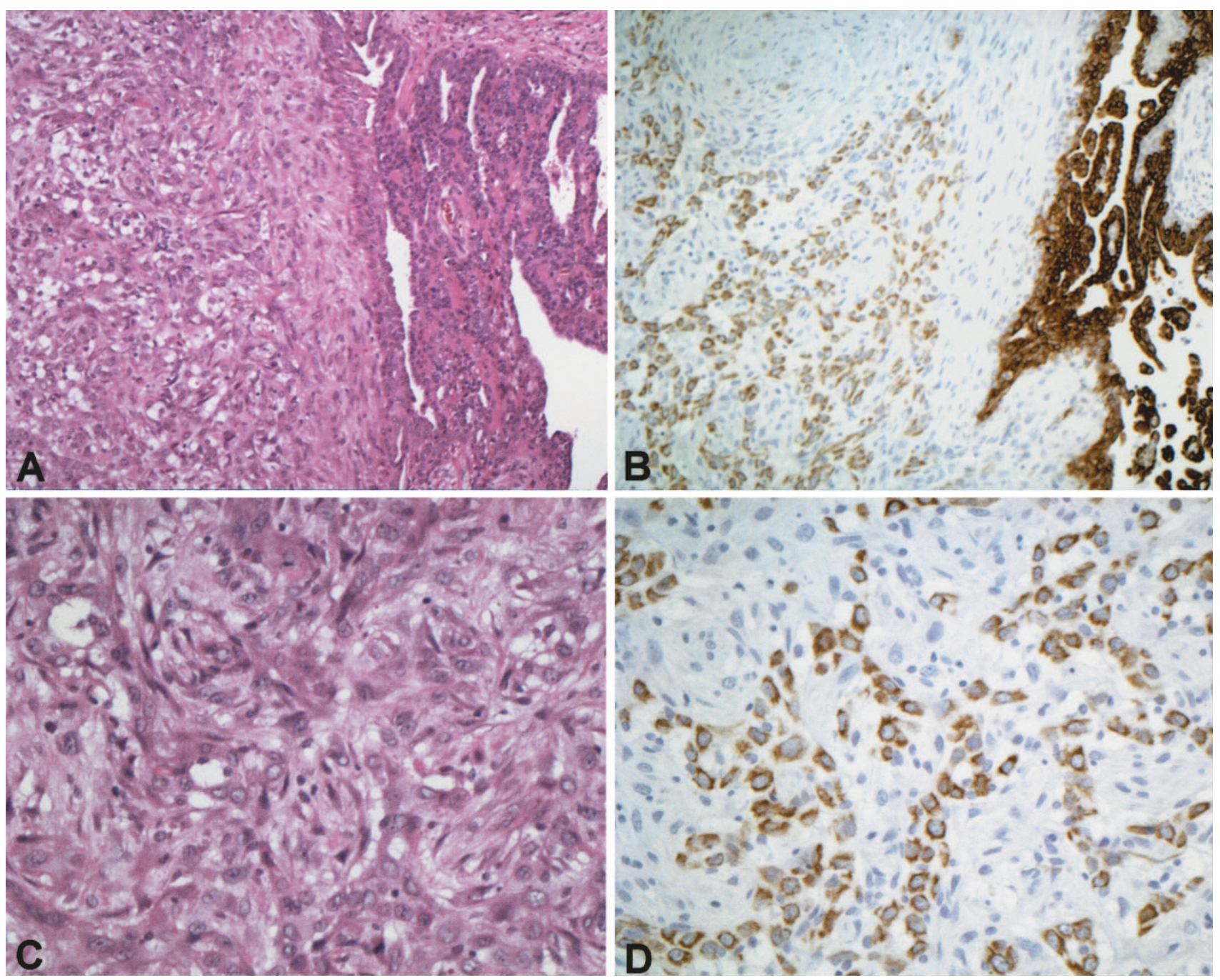

FIGURE 1. A, low-grade spindle cell metaplastic carcinoma arising within papilloma (hematoxylin and eosin; magnification, 100 $\times$ ). B, epithelial cells of papilloma and the metaplastic spindle cells stained for AE1/AE3 (streptavidin-biotin; magnification, 100 $\times$ ). C, detail of the same tumor showing clusters of epithelioid cells (hematoxylin and eosin; magnification, 200×). D, the epithelioid cells and some spindle cells stained for HMW-K (streptavidin-biotin; magnification, 200×).

case) were reviewed, but there was no follow-up information.

Eight of the 33 patients developed local recurrence. In the 8 recurrent cases, the neoplastic nature of the lesion was not recognized in the initial biopsy, and patients did not receive any additional therapy. The cellularity of the initial lesions was very scanty, with a dominant fibromatosis-like pattern and only tiny islands of squamous metaplasia (Fig. 2, A-C). The initial diagnoses on five of these eight cases were CSL, and the remaining three cases were papillomas. Minimal islands resembling squamous metaplasia were usually present (Fig. 2B). The recurrent tumors were more cellular, with increased mitotic activity, as compared with the initial lesions (Fig. 2, C-D). For the two cases that recurred twice, the initial diagnosis was complex sclerosing lesion with tiny islands of squamous metaplasia, and we considered them "nascent" lesions in retrospect. Analysis of the relationship be- tween type of treatment and local recurrence showed that the recurrences were almost directly related to the extensiveness of local excision, with adequate excisions avoiding local recurrences.

\section{DISCUSSION}

In the present study we describe a series of metaplastic tumors arising within fibrosclerotic breast lesions. Most have benign histology of minimal hypocellular epithelial component, including lowgrade adenosquamous and fibromatosis-like metaplastic tumors. However, elements of carcinoma may be present and be large enough to be metastasis capable. There have been only a few case reports of metaplastic tumors associated with papillomas or CSL (8-10). The spindle cell metaplastic tumors of the breast range from very low-grade lesions to high-grade fibrosarcomas (11-13). Two 

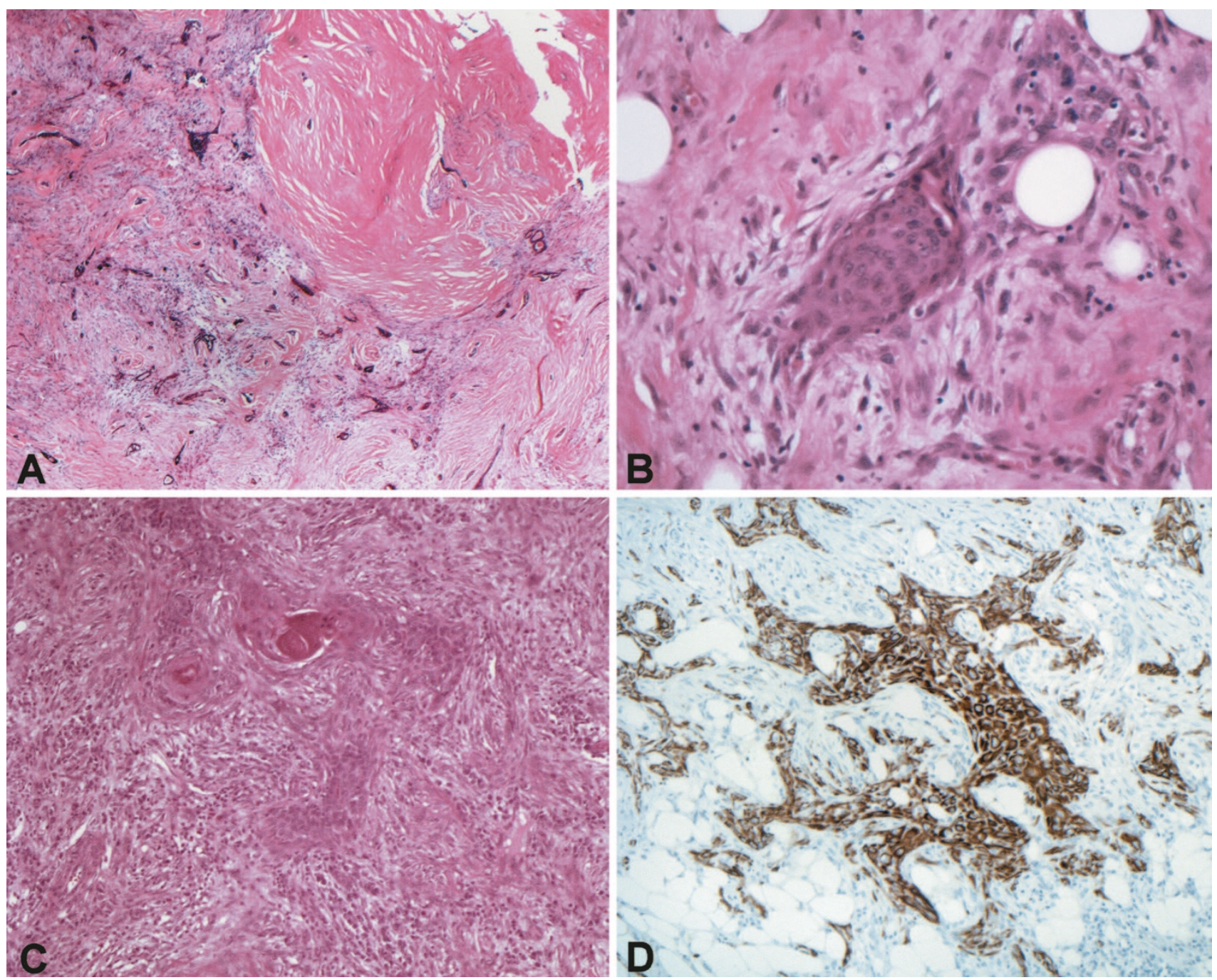

FIGURE 2. A, initial biopsy of a recurrent tumor presenting a low-grade spindle cell metaplastic tumor arising within a background of a complex sclerosing lesion (hematoxylin and eosin; magnification, $100 \times$ ). B, detail of Figure 1A, showing a bland spindle cell proliferation and tiny islands of squamous metaplasia (hematoxylin and eosin; magnification, 200×) C, the recurrent tumor showed increased cellularity and atypia and an adenosquamous pattern (hematoxylin and eosin; magnification, $100 \times$ ). D, the squamous elements and the more epithelioid cells stained for AE1/ AE3 (streptavidin-biotin; magnification, $100 \times$ ).

variants of low-grade metaplastic tumors have been described in association with fibrosclerotic breast lesions: fibromatosis-like tumors with minor epithelial elements (12) and adenosquamous carcinomas $(10,17)$. We previously described a low-grade variant of fibromatosis-like tumor, and in our series some cases arose in a background of CSL (12). Adenosquamous carcinoma, another variant of metaplastic tumor, has also been described in association with papillomas and MP (17). The neoplastic nature of such lesions is sometimes difficult to distinguish from the limited foci of myofibroblastic proliferation that can occur within CSL and papillomas.

Radial scars and CSL are fibrosclerotic lesions mimicking malignancy because of the presence of fibrous tissue proliferation with entrapped glandular elements. The term radial scar has often been used for lesions that are sized $<10 \mathrm{~mm}$, the term
CSL being reserved for those that are larger and usually histologically more complex (15). Radial scars and CSL in the early stages show abundant spindle cells of myofibroblastic origin around the central radiating parenchyma components $(5,15)$. Some investigators have suggested that radial scars are either precursors of carcinomas or may be associated with an increased risk of developing a breast malignancy $(1,3,18,19)$. Denley et al. (10) recently described the first series of five cases of metaplastic carcinomas associated with CSL. Those investigators suggested a potential for sclerosing lesions of the breast to be associated with, and possibly to give rise to, invasive carcinoma of different types. However the nature of the interaction between the pathological processes remains unclear (10).

Haagensen (20) described multiple papillomas or peripheral papillomas as a specific disease entity. 
We elsewhere reported (2) increased incidences of subsequent carcinomas in patients with multiple MP, which may derive from their multiplicity or from atypical epithelial lesions within them. Our findings demonstrated that only papillomas with atypia had an increased risk for subsequent carcinoma in the local region of the original lesion (2). In the present series, 20 of 33 cases of metaplastic tumors arose within papillomas, suggesting a possible association between an unusual form of breast tumor and such fibrosclerotic breast lesion.

Hemorrhagic infarction may be focally present in papillomas and, in the late stages of the ischemic injury, produces an appearance similar to carcinoma with epithelium compressed and distorted into isolated clumps $(6,7)$. Because hemorrhage and both regressive and reactive changes occur spontaneously in fibrosclerotic breast lesions, it is difficult to distinguish those reactive lesions from low-grade metaplastic tumors arising within such lesions. However, such reactive changes are less cellular and lack the more plump spindled cytokeratin-positive cells compared with the tumors reported in the present series. Three cases reviewed, but not included in our series, showed mature bone and/or cartilage within papillomas but were considered only metaplastic and dysplastic changes, not a true neoplastic process. Squamous metaplasia may also be seen in papillomas and sometimes may be extensive, particularly in larger lesions $(6,7)$.

Three cases of the present series arose within nipple adenomas. The nipple adenomas, particularly the syringomatous type, are benign infiltrating neoplasms of the nipple presenting close resemblance to sweat gland duct tumors (21-23). The tumor consists of ductules, small tubules, strands of uniform cells infiltrating the nipple, and sometimes small foci of squamous metaplasia (21-23). Syringomatous adenoma has been considered in the differential diagnosis of adenosquamous carcinomas and tubular carcinomas (17). In our series, the tumors presented features of both spindle cell metaplastic tumor and syringomatous adenoma.

Another group of breast lesions that may share similar features with the low-grade spindle cell metaplastic tumors is the reactive spindle cell nodules that are associated with needle core biopsy and fine-needle aspiration biopsy (24). They probably represent a reactive process occurring in breast after needle biopsy procedures, usually in association with papillary lesions and CSL and not a neoplastic process. They are similar to the postoperative spindle cell nodules described in the genitourinary tract (25). Reactive spindle cell nodules are likely myofibroblastic lesions and must be distinguished from other neoplastic and non-neoplastic spindle cell lesions of the breast (24). Besides the spindle cells with mild to moderate nuclear pleomorphism, the reactive lesions also show thin-walled vessels, hemosiderin-laden macrophages, foam macrophages, and lymphocytes. The spindle cells express vimentin and smooth and specific muscle actins and do not express cytokeratins (24). Awareness and recognition of the reactive spindle cell nodules process may allow avoidance of overdiagnosis of mammary spindle cell malignancy, especially in patients with a history of needle procedures.

Five cases of our present series, in which the neoplastic spindle cells were associated with a complex sclerosing lesion, were not recognized as metaplastic tumors in the initial biopsy. The lesions recurred locally, and in the recurrent lesions the epithelioid clumps, glandular, or squamous elements were more evident than in the initial biopsy, and the diagnosis of a metaplastic tumor was made. The differential diagnosis is difficult and may well be impossible because some radial scars and CSL may show abundant spindle cells (5), and the minimal presence of epithelial cells is often inapparent. To make the diagnosis of a low-grade metaplastic tumor and to avoid overdiagnosis of malignancy in the reactive process, the lesion should present increased cellularity and clumps of cytokeratinpositive plump spindled cells, besides the reactive spindle cells and squamous elements. In our series the original excision had close margins in all eight cases that recurred locally. The coexistence of carcinoma in radial scars and CSL has been described previously $(3,4,15)$. The other three recurrent cases of our series arose within papillomas. The eight recurrent cases of the present series were not recognized as metaplastic tumors in the initial biopsy, and the patients were treated with excisional biopsy only; the tumors recurred locally within 24 to 72 months of the first excision.

Our major purpose in the present article was to describe the histologic features of this rare association between metaplastic tumors and fibrosclerotic breast lesions. Definitive understanding of the histogenesis and biologic potential of these breast metaplastic tumors arising within fibrosclerotic breast lesions will await further experience. However, our results indicate that the behavior and prognosis of these metaplastic lesions is dependent on type, extent, and grade of the metaplastic components. Tumors with a dominant histophenotypic epithelial component have a capacity for axillary node metastasis $(26,27)$. The metaplastic tumors with a dominant spindle cell phenotype show a behavior of fibromatosis or sarcoma, depending on their histological grade. When the carcinomatous component is minimal or not apparent and low grade and the dominant element is phenotypically fibromatosis, then we expect that the clinical behavior of the majority of tumors will be that of fibromatosis. 
The heterogeneity of mixed epithelial-mesenchymal neoplasms in breast should now be recognized. The tumors described here are likely to represent a special subset of breast neoplasms arising in a setting of fibrosclerotic breast lesions: CSL, papillomas, and nipple adenomas with expanded active spindled, squamoid, and rounded cells and sclerotic foci. These few cases of recurrent lesions after excision of CSL or papillomas, with only minimal initial lesions of spindled and epithelial cells of mixed epithelial and mesenchymal histo- and immunophenotype, have obvious practical implications. This is particularly important for core biopsies or incomplete excisions when the margins are close. However, we believe that the infrequent experience of recurrence of these lesions is a result of their rarity and of their usual limited occurrence within papillomas and CSL, leading to their complete removal most often. These active fibrosclerotic foci capable of recurrence as spindled lesions are probably more common in larger and more complex lesions.

Acknowledgments: The authors thank the clinicians and pathologists who provided clinical information and material, particularly Jere Baxter, M.D., and Thomas E. Hanes, M.D., and thank Julia Smith for assistance in obtaining the clinical data and follow-up information.

\section{REFERENCES}

1. Jacobs TW, Byrne C, Colditz G, Connolly JL, Schnitt SJ. Radial scars in benign breast-biopsy specimens and the risk of breast cancer. N Engl J Med 1999;340:430-6.

2. Page DL, Salhany KE, Jensen RA, Dupont WD. Subsequent breast carcinoma risk after biopsy with atypia in a breast papilloma. Cancer 1996;78:258-66.

3. Sloane JP, Mayers MM. Carcinoma and atypical hyperplasia in radial scars and complex sclerosing lesions: importance of lesion size and patient age. Histopathology 1993;23:225-31.

4. Anderson TJ, Battersby S. Radial scars of benign and malignant breasts: comparative features and significance. J Pathol 1985;147:23-32.

5. Battersby S, Anderson TJ. Myofibroblast activity of radial scars. J Pathol 1985;147:33-40.

6. Flint A, Oberman HA. Infarction and squamous metaplasia of intraductal papilloma: a benign breast lesion that may simulate carcinoma. Hum Pathol 1984;15:764-7.

7. Page DL, Anderson TJ. Papilloma and related conditions. In: Diagnostic histopathology of the breast. Edinburgh, Scotland: Churchill Livingstone, 1987: p. 104-20.
8. Pastolero GC, Bowler L, Meads GE. Intraductal papilloma associated with metaplastic carcinoma of the breast [letter]. Histopathology 1997;31:488-90.

9. Pitt MA, Wells S, Eyden BP. Carcinosarcoma arising in a duct papilloma. Histopathology 1995;26:81-4.

10. Denley H, Pinder SE, Tan PH, Sim CS, Brown R, Barker T, et al. Metaplastic carcinoma of the breast arising within complex sclerosing lesion: a report of five cases. Histopathology 2000;36:203-9.

11. Gersell DJ, Katzenstein AL. Spindle cell carcinoma of the breast. A clinicopathologic and ultrastructural study. Hum Pathol 1981;12:550-61.

12. Gobbi H, Simpson JF, Borowsky A, Jensen RA, Page DL. Metaplastic breast tumors with a dominant fibromatosis-like phenotype have a high risk of local recurrence. Cancer 1999; 85:2170-82.

13. Wargotz ES, Deos PH, Norris HJ. Metaplastic carcinomas of the breast. II. Spindle cell carcinoma. Hum Pathol 1989;20: $732-40$

14. Page DL, Anderson TJ. Uncommon types of invasive carcinoma. In: Diagnostic histopathology of the breast. Edinburgh, Scotland: Churchill Livingstone; 1987. p. 236-52.

15. Page DL, Anderson TJ. Radial scars and complex sclerosing lesions of the breast. In: Diagnostic histopathology of the breast. Edinburgh, Scotland: Churchill Livingstone; 1987. p. 89-103.

16. Borowsky A, Gobbi H. Metaplastic carcinoma of the breast: grading and behavior of predominantly spindle cell tumors. Pathol Case Rev 1999;5:208-13.

17. Rosen PP, Ernsberger D. Low-grade adenosquamous carcinoma. A variant of metaplastic mammary carcinoma. Am J Surg Pathol 1987;11:351-8.

18. Fisher ER, Palekar AS, Sass R, Fisher B. Scar cancers: pathologic findings from the National Surgical Adjuvant Breast Project (protocol no. 4)-IX. Breast Cancer Res Treat 1983; 3:39-59.

19. Linell F. Radial scars of the breast and their significance for diagnosis and prognosis. Verh Dtsch Ges Pathol 1985;69: 108-18.

20. Haagensen CD. Multiple intraductal papilloma. In: Diseases of the breast. 3rd ed. Philadelphia: Saunders; 1986. p. 176-91.

21. Jones MW, Norris HJ, Snyder RC. Infiltrating syringomatous adenoma of the nipple. A clinical and pathological study of 11 cases. Am J Surg Pathol 1989;13:197-201.

22. Rosen PP. Syringomatous adenoma of the nipple. Am J Surg Pathol 1983;7:739-45.

23. Slaughter MS, Pomerantz RA, Murad T, Hines JR. Infiltrating syringomatous adenoma of the nipple. Surgery 1992;111: 711-3.

24. Gobbi H, Tse G, Page DL, Olson SJ, Jensen RA, Simpson JF. Reactive spindle cell nodules of the breast after core biopsy or fine-needle aspiration. Am J Clin Pathol 2000;113:288-94.

25. Proppe KH, Scully RE, Rosai J. Postoperative spindle cell nodules of genitourinary tract resembling sarcomas: a report of eight cases. Am J Surg Pathol 1984;8:101-8.

26. Pitts WC, Rojas VA, Gaffey MJ, Rouse RV, Esteban J, Frierson HF, et al. Carcinomas with metaplasia and sarcomas of the breast. Am J Clin Pathol 1991;95:623-32.

27. Kaufman MW, Marti JR, Gallager HS, Hoehn JL. Carcinoma of the breast with pseudosarcomatous metaplasia. Cancer 1984;53:1908-17. 